\title{
BMJ Open Haemodynamic response to crystalloids or colloids in shock: an exploratory subgroup analysis of a randomised controlled trial
}

\author{
Nicholas Heming, ${ }^{1,2}$ Souheil Elatrous, ${ }^{3}$ Samir Jaber, ${ }^{4}$ Anne Sylvie Dumenil, ${ }^{5}$ \\ Joël Cousson, ${ }^{6}$ Xavier Forceville, ${ }^{7}$ Antoine Kimmoun, ${ }^{8}$ Jean Louis Trouillet, ${ }^{9}$ \\ Jérôme Fichet, ${ }^{10}$ Nadia Anguel, ${ }^{11}$ Michael Darmon, ${ }^{12}$ Claude Martin, ${ }^{13}$ \\ Sylvie Chevret, ${ }^{14}$ Djillali Annane, ${ }^{1,2}$ for the CRISTAL Investigators
}

To cite: Heming N, Elatrous S, Jaber S, et al. Haemodynamic response to crystalloids or colloids in shock: an exploratory subgroup analysis of a randomised controlled trial. BMJ Open 2017;7:e016736. doi:10.1136/ bmjopen-2017-016736

- Prepublication history and additional material for this paper are available online. To view, please visit the journal online (http://dx.doi.org/10.1136/ bmjopen-2016-016736).

Received 6 March 2017 Revised 30 July 2017 Accepted 15 August 2017

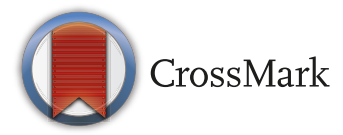

For numbered affiliations see end of article.

Correspondence to Dr Djillali Annane; djillali.annane@aphp.fr

\section{ABSTRACT}

Objective To compare the haemodynamic effect of crystalloids and colloids during acute severe hypovolaemic shock.

Design Exploratory subgroup analysis of a multicentre randomised controlled trial (Colloids Versus Crystalloids for the Resuscitation of the Critically III, CRISTAL, ClinicalTrials. gov NCT00318942).

Setting CRISTAL was conducted in intensive care units in Europe, North Africa and Canada.

Participants Current analysis included all patients who had a pulmonary artery catheter in place at randomisation. 220 patients (117 received crystalloids vs 103 colloids) underwent pulmonary artery catheterisation.

Intervention Crystalloids versus colloids for fluid resuscitation in hypovolaemic shock.

Outcome measures Haemodynamic data were collected at the time of randomisation and subsequently on days 1 , 2, 3, 4, 5, 6 and 7.

Results Median cumulative volume of fluid administered during the first 7 days was higher in the crystalloids group than in the colloids group (3500 (2000-6000) vs 2500 (1000-4000) mL, $p=0.01)$. Patients in the colloids arm exhibited a lower heart rate over time compared with those allocated to the crystalloids arm $(p=0.014)$. There was no significant difference in Cardiac Index $(p=0.053)$, mean blood pressure $(p=0.4)$, arterial lactates $(p=0.9)$ or global Sequential Organ Failure Assessment score $(p=0.3)$ over time between arms.

Conclusions During acute severe hypovolaemic shock, patients monitored by a pulmonary artery catheter achieved broadly similar haemodynamic outcomes, using lower volumes of colloids than crystalloids. The heart rate was lower in the colloids arm.

\section{INTRODUCTION}

Fluid resuscitation is a cornerstone of the management of hypovolaemia. ${ }^{1}$ During hypovolaemic shock, fluids restore intravascular volume, cardiac output, oxygen delivery and reverse peripheral hypoperfusion. ${ }^{2}$ Resuscitation fluids are divided into two distinct
Strengths and limitations of this study

- Large international multicentre trial, comparing the haemodynamic effect of crystalloids vs colloids in severe hypovolaemic shock. The subgroup analysis met recognised criteria of robustness.

- The Colloids Versus Crystalloids for the Resuscitation of the Critically III trial was a pragmatic, open label trial.

- Pulmonary artery catheter monitoring was left at the patient's physician discretion resulting in missing data.

- Results should be considered exploratory.

categories, crystalloids and colloids. ${ }^{3}$ On the one hand, crystalloids dilute the plasma protein content, reducing plasma oncotic pressure which may result in interstitial oedema. The most commonly used crystalloid, isotonic saline, induces hyperchloraemic acidosis and acute kidney injury. ${ }^{4-6}$ On the other hand, colloids are composed of large molecules, increasing their vascular retention and are theoretically more effective for fluid resuscitation. ${ }^{78}$ However, the most commonly used colloid, starch, is associated with acute kidney injury, increased need for renal replacement therapy, accumulation in reticuloendothelial tissues and increased requirements for blood products. ${ }^{9-11}$ A series of large clinical trials were recently undertaken aimed at determining which fluid was superior for the resuscitation of critically ill patients. ${ }^{12-16}$

The Colloids Versus Crystalloids for the Resuscitation of the Critically Ill (CRISTAL) trial addressed the issue using a pragmatic approach; rather than studying one fluid versus another, both categories of fluids, crystalloids and colloids, were compared in 
severe hypovolaemia. ${ }^{17}$ The CRISTAL trial included 2857 subjects treated in 57 intensive care units (ICUs). The primary outcome, 28-day mortality, did not significantly differ, with $25.4 \%$ mortality in the colloids arm vs $27 \%$ in the crystalloids arm. This finding was similar to results from previous large trials comparing a single colloid to a single crystalloid. ${ }^{13-15}$ However, mortality by 90 days was significantly lower in the colloids arm than in the crystalloids arm $(30.7 \%$ vs $34.2 \%)$. This finding was deemed exploratory. Additionally, the number of days alive at 7 and 28 days without vasopressor therapy was higher in the colloids than in the crystalloids arm. We sought to compare the effect of crystalloids with that of colloids on haemodynamic parameters during hypovolaemic shock. The pulmonary artery catheter (PAC) provides a reliable and reproducible measure of cardiac output as well as the pulmonary artery pressure, pulmonary artery occlusion pressure (PAOP) and derived variables. ${ }^{18}$ Therefore, the current study aimed at assessing the haemodynamic effect of crystalloids vs colloids in the CRISTAL participants monitored by PAC.

\section{MATERIALS AND METHODS}

\section{Study setting and patients}

The current study is a subgroup analysis of a randomised multicentre trial (CRISTAL, ClinicalTrials.gov NCT00318942), comparing the effect of crystalloid vs colloid administration for fluid resuscitation in the ICU on mortality at 28 days. ${ }^{17}$ CRISTAL was a non-blinded, pragmatic study. Included subjects were randomised to receive either crystalloids or colloids for hypovolaemia. Crystalloids consisted of isotonic or hypertonic saline as well as buffered solutions, whereas colloids comprised albumin, gelatins, dextrans and hydroxyethyl starches. Patients were managed throughout their ICU stay with the same fluid category. The type of fluid within the assigned group as well as the amount of fluid to be administered was determined by the physician in charge of the patient, the daily total dose of hydroxyethyl starch being restricted to no more than $30 \mathrm{~mL} / \mathrm{kg}$ of body weight. Physicians could administer albumin in response to demonstrated hypoalbuminaemia. ${ }^{17}$ The study protocol was approved by local institutional review boards. Deferred informed consent was obtained from participants or legally authorised surrogates.

For the current ancillary study, among the CRISTAL population, we included all patients who had PAC in place as part of their routine management either prior to or within the first 24 hours of randomisation.

\section{Data collection}

\section{Demographic and general characteristics}

The following data were prospectively collected at the time of randomisation: age, gender, weight, source of admission, McCabe class ${ }^{19}$ and Disability Scale Score. ${ }^{20}$ Severity scores included the Glasgow Coma Scale, ${ }^{21}$ Simplified Acute Physiology Score II $^{22}$ and the Sequential
Organ Failure Assessment (SOFA) score. ${ }^{23}$ Causes of acute hypovolaemia were stratified in the initial trial as sepsis, trauma or other disorders. We collected a set of symptoms and biological signs of acute hypovolaemia (online supplementary table S1).

\section{Haemodynamic variables}

We prospectively measured, for as long as PAC was in place or up to 7 days (whichever occurred first), before randomisation and then once daily (by recording the first value reported in the medical file following the change of shift, ie, typically around 08:00 hours) the following haemodynamic data: heart rate; systolic, diastolic and mean blood pressure; central venous pressure (CVP); systolic, diastolic and mean pulmonary artery pressure; PAOP; Cardiac Index and urinary output. Additionally, mean blood pressure was recorded hourly following the first 24 hours after randomisation. We calculated, using standard formulas, the product of the heart rate and systolic blood pressure (or rate-pressure product (RPP)), a marker of myocardial perfusion requirement, systemic and pulmonary vascular resistances, Stroke Volume Index and Left and Right Ventricular Stroke Work Index. Laboratory values included arterial $\mathrm{pH}$, bicarbonate, lactate and mixed venous oxygen saturation $\left(\mathrm{SvO}_{2}\right.$.). Finally, to compare colloids with crystalloids in reaching the haemodynamic targets of the 6-hour bundles of the Surviving Sepsis Campaign, we collected these same variables 6 hours after randomisation. ${ }^{24}$

\section{Other variables}

We collected before randomisation and daily up to 7 days postrandomisation, the SOFA score and the cumulative volume of administered fluids and throughout the trial the occurrence of the main interventions including packed red cell transfusion and the administration of vasopressors.

\section{Statistical analysis}

Quantitative variables are expressed as median (IQR) and categorical variables as number (percentage). The 7-day time course of mean, systolic and diastolic blood pressure, CVP, heart rate, Cardiac Index and daily diuresis as well as the results of arterial blood gases was compared between arms. We then compared systolic, diastolic and mean pulmonary artery pressure and PAOP in both arms. In order to further explore differences between arms, we calculated the RPP as well as the various indexes derived from the use of PAC. Mixed effects models, which are appropriate for clustered and dependent data, were used to study the relationship between treatment arms and the time course of haemodynamic variables as well as the global SOFA score. ${ }^{25}$ The area under the curve of mean blood pressure was estimated for each individual, over the first 24 hours, using polynomial integration and compared using the Wilcoxon rank-sum test. Number of days alive without vasopressor therapy was compared using the Wilcoxon rank-sum test. The proportion of 
patients reversing signs of hypoperfusion (mean blood pressure (MAP) $\geq 65 \mathrm{~mm} \mathrm{Hg}$, urine output $\geq 0.5 \mathrm{~mL} / \mathrm{kg}$ / hour, CVP between 8 and $12 \mathrm{~mm} \mathrm{Hg}$ and $\mathrm{SvO}_{2} \geq 65 \%$, within the first 6 hours of resuscitation) in the sepsis subgroup was compared using the Fisher's exact test. ${ }^{26}$ Complete case analysis was undertaken. Since the current analysis was deemed exploratory and since we report on all statistical analysis done, no correction for multiples testing was deemed necessary. Statistical analyses were performed using SAS V.9.3 (SAS) and R V.2.13.0 (http:/ / www.R-project.org/) software. Tests were two sided. A value of $\mathrm{p}<0.05$ was considered significant.

\section{RESULTS}

Patients

Among the CRISTAL population, 220 subjects had PAC in place as part of their routine management, of which
103 received colloids and 117 crystalloids, accounting for a total of 645 catheter-days. PAC was generally in place around the time of randomisation, either before $(n=79$; $36 \%)$ or within 24 hours postrandomisation $(n=84$; $38 \%$ ). Characteristics of the subgroup of PAC-monitored patients were similar to those of the whole population of the CRISTAL study, regarding age, gender and initial severity scores (table 1). Haemodynamic variables at the time of randomisation are described in table 2.

\section{Treatment effects on haemodynamic variables}

Median cumulative volume of fluid administered during the first 7 days in the ICU was higher in the crystalloids than in the colloids arm $(3500(2000-6000)$ vs 2500 (1000-4000) $\mathrm{mL}$, respectively $(\mathrm{p}=0.01)$. The distribution of fluid types within each study arm is displayed in online supplementary table S2. During the first 24 hours following randomisation, mean blood pressure did not

\begin{tabular}{|c|c|c|c|c|}
\hline & $\begin{array}{l}\text { All patients } \\
n=220\end{array}$ & $\begin{array}{l}\text { Colloids arm } \\
n=103\end{array}$ & $\begin{array}{l}\text { Crystalloids arm } \\
\mathrm{n}=117\end{array}$ & p Value \\
\hline Age, median (IQR), years & $68(57-77)$ & $69(59-79)$ & $67(52-75)$ & 0.05 \\
\hline Male sex, no (\%) & $141(64.1)$ & $71(68.9)$ & $70(59.8)$ & 0.20 \\
\hline Weight, median (IQR), kg & $72(63-85)$ & $71.3(62.3-84.5)$ & $73.4(64-88)$ & 0.49 \\
\hline Reason for ICU admission, no (\%) & & & & 0.58 \\
\hline Medical & $148(67.3)$ & $70(68)$ & $78(66.7)$ & \\
\hline Scheduled surgery & $41(18.6)$ & $20(19.4)$ & $21(17.9)$ & \\
\hline Emergency surgery & 29 (13.2) & $12(11.7)$ & $17(14.5)$ & \\
\hline Non-surgical trauma & $2(0.9)$ & $1(1)$ & $1(0.9)$ & \\
\hline Source of admission to ICU, no (\%) & & & & 0.11 \\
\hline Community & $104(47.3)$ & $39(37.9)$ & $65(55.6)$ & \\
\hline Hospital ward & $102(46.4)$ & $56(54.4)$ & 46 (39.3) & \\
\hline Other ICU & $11(5)$ & $7(6.8)$ & $4(3.4)$ & \\
\hline Long-term care facility & $3(1.3)$ & $1(0.9)$ & $2(1.7)$ & \\
\hline McCabe class, no (\%) & & & & 0.83 \\
\hline No underlying disease or no fatal disease & $129(58.6)$ & $62(60.2)$ & $67(57.3)$ & \\
\hline Underlying ultimately fatal disease (>5years) & $83(37.7)$ & $38(36.9)$ & $45(38.5)$ & \\
\hline Underlying rapidly fatal disease ( $<1$ year) & $8(3.6)$ & $3(2.9)$ & $5(4.3)$ & \\
\hline Knaus Disability Scale, no (\%) & & & & 0.28 \\
\hline A & $35(15.9)$ & $15(14.6)$ & $20(17.1)$ & \\
\hline B & $82(37.3)$ & $33(32)$ & $49(41.9)$ & \\
\hline C & $64(29.1)$ & $33(32)$ & $31(26.5)$ & \\
\hline $\mathrm{D}$ & $37(16.8)$ & $20(19.4)$ & $17(14.5)$ & \\
\hline Glasgow Coma Scale score, median (IQR) & $11(3-15)$ & $13(3-15)$ & $11(3-15)$ & 0.61 \\
\hline SAPS II, median (IQR) & $50(33-65)$ & $51(36-66)$ & $50(30-64)$ & 0.41 \\
\hline SOFA, median (IQR) & $8(5-11)$ & $8(5-11)$ & $9(5-12)$ & 0.80 \\
\hline Sepsis, no (\%) & $108(49.1)$ & $52(50.5)$ & $56(47.9)$ & 0.79 \\
\hline
\end{tabular}

Knaus Scale A. prior good health and no functional limitations; B. mild to moderate limitation of activity owing to chronic medical problem; C. chronic disease producing serious but not incapacitating restriction of activity; D, severe restriction of activity due to disease; includes persons bedridden or institutionalised due to illness.

ICU, intensive care unit; SAPS II, Simplified Acute Physiology Score II; SOFA, Sequential Organ Failure Assessment. 
Table 2 Physiological values at baseline according to randomisation

\begin{tabular}{|c|c|c|c|c|}
\hline & $\begin{array}{l}\text { All patients } \\
\mathrm{n}=\mathbf{2 2 0}\end{array}$ & $\begin{array}{l}\text { Colloids arm } \\
n=103\end{array}$ & $\begin{array}{l}\text { Crystalloids arm } \\
\mathrm{n}=117\end{array}$ & p Value \\
\hline Heart rate, median (IQR), beats/min $(n=218)$ & $100(89-120)$ & $99(88-115)$ & $103.5(90-124)$ & 0.25 \\
\hline $\begin{array}{l}\text { Diastolic blood pressure, median (IQR), mm } \\
\mathrm{Hg}(n=181)\end{array}$ & $48(40-58)$ & $47(37-57)$ & $50(41-58)$ & 0.19 \\
\hline $\begin{array}{l}\text { Central venous pressure, median (IQR), mm } \\
\mathrm{Hg}(\mathrm{n}=81)\end{array}$ & $9(7-12)$ & $10(6-12)$ & $9(7-13)$ & 0.96 \\
\hline $\begin{array}{l}\text { Pulmonary artery systolic pressure, } \\
\text { median (IQR), mm Hg }(n=64)\end{array}$ & $32(27-39)$ & $32(25-40)$ & $32(27-38)$ & 0.59 \\
\hline $\begin{array}{l}\text { Pulmonary artery occlusion pressure, median } \\
\text { (IQR), } \mathrm{mm} \mathrm{Hg}(n=53)\end{array}$ & $12(8-15)$ & $12(7-15)$ & $12(9-16)$ & 0.30 \\
\hline Cardiac Index, median (IQR), L/min/m² $(n=75)$ & $2.5(2-3.1)$ & $2.4(2.2-3)$ & $2.5(2-3.3)$ & 0.94 \\
\hline $\begin{array}{l}\text { Systemic vascular resistance, median (IQR), } \\
(\text { dyn } s) / \mathrm{cm}^{5}(n=49)\end{array}$ & $893(690-1208)$ & $906(699-1146)$ & $830(637-1238)$ & 0.40 \\
\hline $\begin{array}{l}\text { Pulmonary vascular resistance, median (IQR), } \\
(\text { dyn } s) / \mathrm{cm}^{5}(\mathrm{n}=33)\end{array}$ & $170(121-260)$ & $172(135-343)$ & $0.35(120-230)$ & \\
\hline $\begin{array}{l}\text { Stroke Volume Index, median (IQR), } \mathrm{mL} / \mathrm{m}^{2} \\
(\mathrm{n}=74)\end{array}$ & $26(21-34)$ & $27(22-34)$ & $24(20-33)$ & 0.40 \\
\hline Lactate, median (IQR), mmol/L $(\mathrm{n}=155)$ & $2.3(1.3-4.9)$ & $2.3(1.3-4.6)$ & $2.25(1.4-5)$ & 0.94 \\
\hline $\mathrm{SvO}_{2}$, median (IQR), \% $(\mathrm{n}=33)$ & $71(58-80)$ & $63(58-73)$ & $74(57-81)$ & 0.31 \\
\hline
\end{tabular}

$\mathrm{SvO}_{2}$, mixed venous oxygen saturation.

significantly differ between treatment arm (mean area under the curve 78 (68-84) for colloids vs 77 (70-84) $\mathrm{mm} \mathrm{Hg}$ /hour for crystalloids $(\mathrm{p}=0.6))$. The heart rate was lower in the colloids than in the crystalloids group $(\mathrm{p}=0.014)$ (figure 1). Systolic, diastolic and mean blood pressure did not significantly differ between arms ( $\mathrm{p}=0.6, \mathrm{p}=0.2$ and $\mathrm{p}=0.4$, respectively) (online supplementary figure S1-S3). Cardiac Index, although the difference was not statistically significant $(p=0.053)$, was higher in patients treated with colloids compared with those treated with crystalloids (figure 2). CVP did not differ between both arms $(p=0.9)$ (online supplementary figure S4). Subjects in the colloids arm exhibited a lower $\operatorname{RPP}(\mathrm{p}=0.036)$ (figure 3). Arterial $\mathrm{pH}$, arterial levels of bicarbonate and lactate did not differ between groups $(\mathrm{p}=0.3, \mathrm{p}=0.3$ and $\mathrm{p}=0.9$, respectively) (online supplementary figure $\mathrm{S} 5-\mathrm{S} 7$ ). $\mathrm{SvO}_{2}$, daily urine output (online supplementary figure S8) and the SOFA score did not differ between both arms $(\mathrm{p}=0.9$, $\mathrm{p}=0.15$ and $\mathrm{p}=0.3$, respectively). Haemodynamic stability was reached through a similar use of vasopressors and a similar use of blood transfusion (table 3). Other relevant outcomes did not significantly differ between both groups. No serious adverse event related to PAC placement was reported during the trial.

Isotonic saline solutions and hydroxyl starches were the most common types of administered fluids, among, respectively crystalloids and colloids groups. We therefore compared the overall time course of haemodynamic parameters between isotonic saline-treated patients and those treated with hydroxyethyl starches. Treatment with hydroxyethyl starches was associated with a lower heart rate $(\mathrm{p}=0.023)$ and a lower RPP $(\mathrm{p}=0.042)$ compared with isotonic saline. 


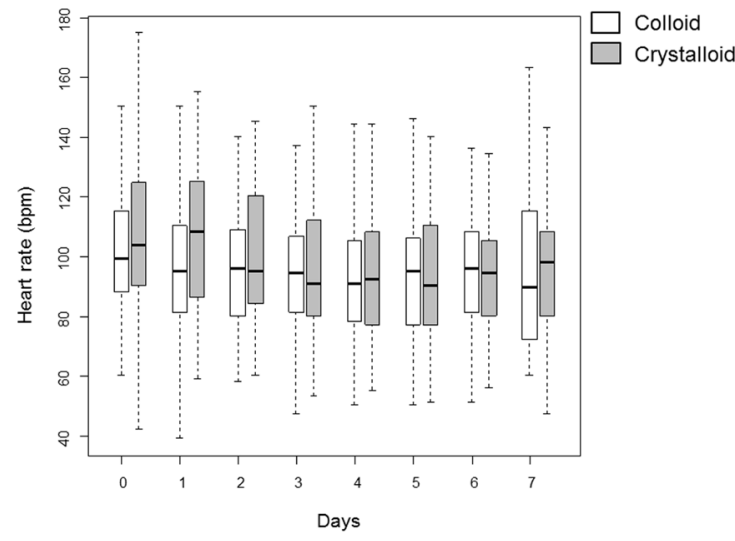

Figure 1 Box plot showing heart rate distribution over the first 7 days following randomisation in both arms. The horizontal line in the box indicates the median value, whereas the lines at the top and bottom of the box indicate IQR. Day 0 , day of randomisation. bpm, beats $/ \mathrm{min}$.

\section{Sepsis subgroup}

Among PAC-monitored patients, 108 subjects were stratified in the sepsis group, of which 52 were allocated to colloids and 56 to crystalloids. We compared the number of patients achieving mean blood pressure levels $\geq 65 \mathrm{~mm}$ $\mathrm{Hg}$ and urine output $\geq 0.5 \mathrm{~mL} / \mathrm{kg} /$ hour within the first 6 hours. ${ }^{24}$ A total of $35 / 51(69 \%)$ patients in the crystalloids arm achieved MAP $\geq 65 \mathrm{~mm} \mathrm{Hg}$ after 6 hours vs $31 / 47$ $(66 \%)$ in the colloids arm $(\mathrm{p}=0.8) ; 25 / 38(66 \%)$ patients in the crystalloids arm achieved urine output $\geq 0.5 \mathrm{~mL} /$ $\mathrm{kg}$ /hour after 6 hours vs $17 / 28(61 \%)$ in the colloids $\operatorname{arm}(p=0.8)$. Limited data precluded the analysis of CVP and $\mathrm{SvO}_{2}$ values during the first 6 hours following randomisation.

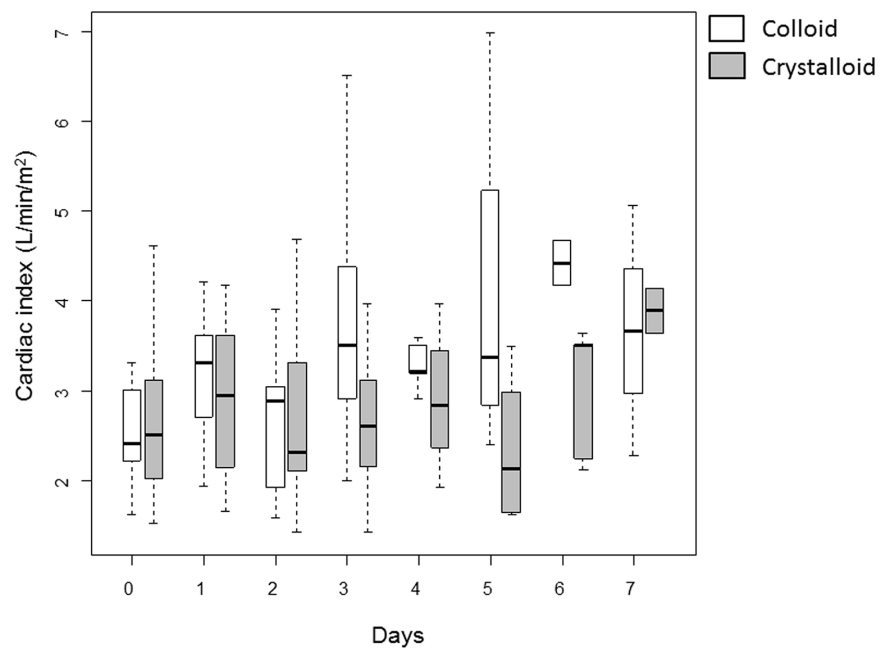

Figure 2 Box plot showing Cardiac Index distribution over the first 7 days following randomisation in both arms. The horizontal line in the box indicates the median value, whereas the lines at the top and bottom of the box indicate IQR. Day 0 , day of randomisation.

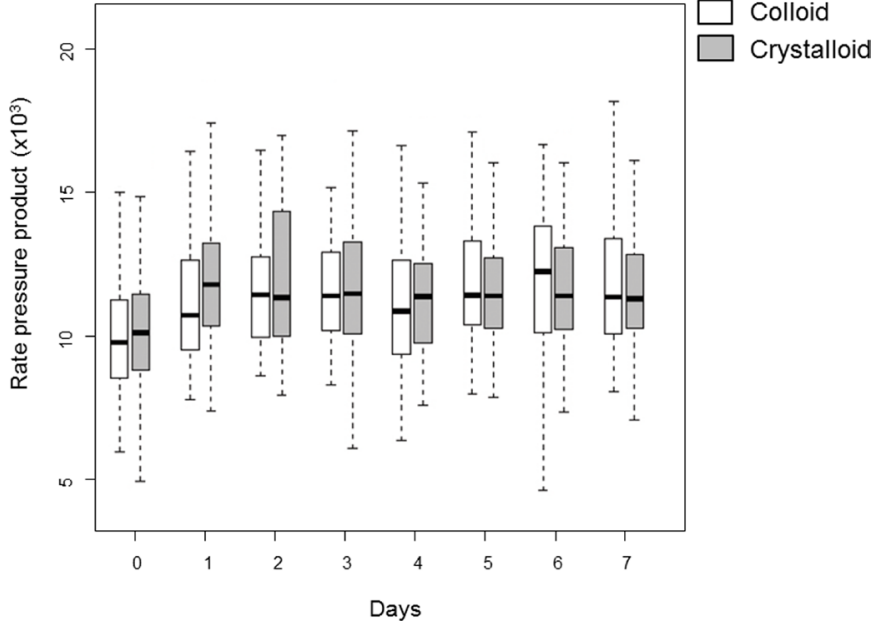

Figure 3 Box plot showing the rate-pressure product distribution over the first 7 days following randomisation in both arms. The horizontal line in the box indicates the median value, whereas the lines at the top and bottom of the box indicate IQR. Day 0, day of randomisation.

\section{DISCUSSION}

We found that colloids achieved broadly similar resuscitation goals to crystalloids using lower volumes of administered fluids. Additionally, colloids may exhibit a favourable impact on heart rate and RPP. Colloids did not affect any other haemodynamic endpoints. We found, in patients with sepsis, no evidence for a superiority of colloids over crystalloids in achieving haemodynamic targets of the 6-hour bundle of the Surviving Sepsis Campaign. ${ }^{24}$ The fact that the mean arterial blood pressure and Cardiac Index did not significantly differ in both groups may be explained by the fact that physicians sought to achieve similar targets in both groups, whether by the administration of fluids, packed red cell or vasopressors.

Tachycardia may increase myocardial work, with subsequent excessive myocardial energy expenditure, ${ }^{27}$ and may be associated with worse outcomes through excessive cardiovascular morbimortality. ${ }^{28}{ }^{29}$ Myocardial protection is of particular interest in the ageing population currently common in most ICUs, since it may somewhat relieve cardiovascular mortality.

Table 3 Study outcome and blood transfusion by treatment group

\begin{tabular}{|c|c|c|c|}
\hline & $\begin{array}{l}\text { Colloids arm } \\
(n=103)\end{array}$ & $\begin{array}{l}\text { Crystalloids } \\
\text { arm } \\
(n=117)\end{array}$ & p Value \\
\hline \multicolumn{4}{|l|}{$\begin{array}{l}\text { Number of days alive } \\
\text { without, median (IQR) }\end{array}$} \\
\hline $\begin{array}{l}\text { Vasopressor } \\
\text { therapy within the } \\
\text { first } 28 \text { days }\end{array}$ & $18(0-25)$ & $20(0-24)$ & 0.98 \\
\hline $\begin{array}{l}\text { Units of packed } \\
\text { red cell transfused, } \\
\text { median (IQR) }\end{array}$ & $2(2-3)$ & $2(2-4)$ & 0.59 \\
\hline
\end{tabular}


The efficacy of fluid resuscitation is determined by the capacity of administered fluids to remain in the intravascular space. ${ }^{1}$ The superior oncotic pressure of colloids is associated with increased intravascular expansion capacity compared with crystalloids. In order to achieve similar resuscitation goals, compared with colloids, between $20 \%$ and $50 \%$ more volume of crystalloids should be administered. ${ }^{12131730}$ Inflammatory states such as those observed during critical illness are usually associated with endothelial dysfunction, leading to interstitial oedema. Reducing volumes of administered fluids may be of clinical benefit, and a negative fluid balance improved outcome in Acute Respiratory Distress Syndrome, a frequent complication of sepsis. ${ }^{31} 32$ In septic shock, a positive fluid balance has been associated with a worse outcome. ${ }^{33}$ However, short-term haemodynamic benefits of fluids may in some cases be offset by long-term deleterious consequences. Indeed, some types of colloids may be unsafe. Starches, the most commonly used colloid, may be associated with increased risk of acute kidney injury and increased need for renal replacement therapy, both in the general ICU population and in sepsis. ${ }^{121316}$ The daily total volume of hydroxyethyl starch which could not exceed $30 \mathrm{~mL} / \mathrm{kg}$ in the CRISTAL trial led patients having exceeded that limit to subsequently receive albumin or crystalloids. The use of starches has now been restricted in the ICU in Europe and the USA. ${ }^{34}{ }^{35}$ The implication is that from a haemodynamic point of view, fluid resuscitation with colloids or crystalloids is broadly equivalent—maybe with a slight advantage for colloids-although the price of resuscitation using crystalloids would be an increase in the total volume of administered fluids.

Our findings are similar to those of several of the other major fluid trials. Most trials compared one type of colloid with one type of crystalloid. The Saline versus Albumin Fluid Evaluation (SAFE) study assessed $4 \%$ albumin or 9\%o saline in critically ill patients. ${ }^{14}$ Albumin administration was associated with a statistically significant lower heart rate on the first day of treatment, although the difference was small. The Albumin Italian Outcome Sepsis (ALBIOS) study compared 20\% albumin (titrated to achieve a serum albumin concentration of over $30 \mathrm{~g} / \mathrm{L}$ ) to $9 \%$ saline in patients suffering from severe sepsis. ${ }^{15}$ Over the first 7 days after randomisation, patients in the albumin arm experienced lower heart rate and a shorter duration of vasopressor therapy. The Crystalloid versus Hydroxyethyl Starch Trial (CHEST) trial randomised critically ill patients to receive hydroxyethyl starches or $9 \%$ o saline. ${ }^{13}$ Among the various haemodynamic targets, higher CVP over the first 4 days following randomisation was the only statistically significant difference between hydroxyethyl starches and 9\%o saline-treated patients. The authors of the CHEST study concluded that crystalloids were as effective as colloids for initial resuscitation. The Scandinavian Starch for Severe Sepsis/Septic Shock (6S) trial allocated either hydroxyethyl starches or Ringer's acetate to severe sepsis patients. ${ }^{12}$ The haemodynamic targets were similar between both arms over the first 24 hours after randomisation. Of note, subjects enrolled in both CHEST and 6S studies were enrolled up to 24 hours after their admission to the ICU, hence after the initial resuscitation phase. However, in CRISTAL, patients were randomised and treated as early as possible after the occurrence of shock. Patients in CRISTAL were treated by a variety of colloids including starches, but also gelatins, in approximately one-third of patients. Gelatins have been less extensively studied in large clinical trials, and their drawbacks are not as well characterised. Their use may have somewhat offset any deleterious effect related to starches when administered in the colloid group. Overall, these findings should help expand our knowledge pertaining to the field of fluid resuscitation.

Our study has some limitations. First, our subgroup accounts for less than $10 \%$ of the global CRISTAL trial population; the small size of our subgroup is related to a steady decline in the use of the PAC during the CRISTAL trial, amidst reports that the use of PAC does not alter outcome in ICU patients and increased availability of less invasive haemodynamic monitoring tools. Moreover, some selection bias may have been introduced, owing to the fact that PA catheterisation was not performed within 24 hours of randomisation in about one-fourth of the sample. Complete case analyses performed on available measurements further assume that missing mechanisms were unrelated to patient status. Finally, some inflation of type I error rate associated with the number of tests undertaken is possible, meaning that interpretation of results should be exploratory.

\section{CONCLUSION}

CRISTAL participants monitored by a PAC reached broadly similar haemodynamic outcomes whether treated by crystalloids or by colloids. Colloids were associated with lower heart rates and lower volume of administered fluids than crystalloids.

\section{Author affiliations}

${ }^{1}$ General Intensive Care Unit, Raymond Poincaré Hospital, Garches, France ${ }^{2}$ U1173 Lab Inflammation\& Infection, University of Versailles SQY-Paris Saclay INSERM, Garches, France

${ }^{3}$ service de réanimation, Centre Hospitalo-Universitaire Tahar Sfar, University of Monastir, Mahdia, Tunisia

${ }^{4}$ Saint Eloi University Hospital, Montpellier, France

${ }^{5}$ Antoine Béclère Hospital, Clamart, France

${ }^{6}$ Reims University Hospital, Robert Debré Hospital, Reims, France

${ }^{7}$ General Hospital, Meaux, France

${ }^{8}$ Intensive Care Unit Brabois, Heart and Vessels Institute, Nancy University Hospital, Nancy, France

${ }^{9}$ Pitié Salpêtrière Hospital, Paris, France

${ }^{10}$ Centre Cardiologique du Nord, Saint-Denis, France

${ }^{11}$ Bicêtre Hospital, Le Kremlin-Bicêtre, France

${ }^{12}$ Saint Louis Hospital, Paris, France

${ }^{13}$ AP-HM Hôpital Nord, Marseille, France

${ }^{14}$ Biostatistic Team, Saint Louis Hospital, Paris, France

Acknowledgements We thank all the investigators and patients of the CRISTAL trial. We would like to thank Cendrine Chaffaut of the Biostatistic Team, Saint Louis Hospital for her technical assistance. 
Contributors NH, SC and DA were involved in study concept and design. NH, SE, SJ, ASD, JC, XF, AK, JLT, JF, NA, MD and CM acquired the data; SC was involved in statistical analysis; NH, SC and DA were involved in analysis and interpretation of data; $\mathrm{NH}$ and DA drafted the manuscript; all authors critically revised the manuscript for important intellectual content; DA was involved in study supervision; all authors read and approved the final manuscript.

Funding The CRISTAL study was funded by 2001 and 2010 grants (AOM 01020 ) from the French Ministry of Health.

Competing interests None declared.

Ethics approval Committee for the Protection of People of Saint-Germain-en-Laye for French sites and at institutional review boards elsewhere.

Provenance and peer review Not commissioned; externally peer reviewed.

Data sharing statement Individual data are available by contacting DA at djillali. annane@aphp.fr.

Open Access This is an Open Access article distributed in accordance with the Creative Commons Attribution Non Commercial (CC BY-NC 4.0) license, which permits others to distribute, remix, adapt, build upon this work non-commercially, and license their derivative works on different terms, provided the original work is properly cited and the use is non-commercial. See: http://creativecommons.org/ licenses/by-nc/4.0/

(C) Article author(s) (or their employer(s) unless otherwise stated in the text of the article) 2017. All rights reserved. No commercial use is permitted unless otherwise expressly granted.

\section{REFERENCES}

1. Myburgh JA, Mythen MG. Resuscitation fluids. N Engl J Med 2013;369:1243-51.

2. Guyton AC, Hall JE. Textbook Of Medical Physiology. Philadelphia: Saunders, 2005.

3. Myburgh JA. Fluid resuscitation in acute medicine: what is the current situation? J Intern Med 2015;277:58-68.

4. Scheingraber S, Rehm M, Sehmisch C, et al. Rapid saline infusion produces hyperchloremic acidosis in patients undergoing gynecologic surgery. Anesthesiology 1999;90:1265-70.

5. Orbegozo Cortés D, Rayo Bonor A, Vincent JL. Isotonic crystalloid solutions: a structured review of the literature. $\mathrm{Br} J$ Anaesth 2014;112:968-81.

6. Yunos NM, Bellomo R, Hegarty C, et al. Association between a chloride-liberal vs chloride-restrictive intravenous fluid administration strategy and kidney injury in critically ill adults. JAMA 2012;308:1566-72.

7. Verheij J, van Lingen A, Beishuizen A, et al. Cardiac response is greater for colloid than saline fluid loading after cardiac or vascular surgery. Intensive Care Med 2006;32:1030-8.

8. Trof RJ, Sukul SP, Twisk JW, et al. Greater cardiac response of colloid than saline fluid loading in septic and non-septic critically ill patients with clinical hypovolaemia. Intensive Care Med 2010;36:697-701.

9. Wiedermann CJ, Bellomo R, Perner A. Is the literature inconclusive about the harm from HES? No. Intensive Care Med 2016 (Published Online First: 23 March 2016).

10. Ertmer $C$, Annane D, Van Der Linden $P$. Is the literature inconclusive about the harm from HES? Yes. Intensive Care Med 2016 (Published Online First: 23 March 2016).

11. Schetz M, Shaw $A D$, Vincent $J$-L. Is the literature inconclusive about the harm of HES? We are not sure. Intensive Care Med;120.

12. Perner A, Haase N, Guttormsen AB, et al. Hydroxyethyl starch $130 / 0.42$ versus Ringer's acetate in severe sepsis. N Engl $J$ Med 2012;367:124-34.

13. Myburgh JA, Finfer S, Bellomo R, et al. Hydroxyethyl starch or saline for fluid resuscitation in intensive care. $N$ Engl $J$ Med 2012;367:1901-11.

14. Finfer S, Bellomo R, Boyce N, et al. A comparison of albumin and saline for fluid resuscitation in the intensive care unit. N Engl J Med 2004;350:2247-56.
15. Caironi P, Tognoni G, Masson S, et al. Albumin replacement in patients with severe sepsis or septic shock. N Engl J Med 2014;370:1412-21.

16. Brunkhorst FM, Engel C, Bloos F, et al. Intensive insulin therapy and pentastarch resuscitation in severe sepsis. N Engl J Med 2008;358:125-39.

17. Annane D, Siami S, Jaber S, et al. Effects of fluid resuscitation with colloids vs crystalloids on mortality in critically ill patients presenting with hypovolemic shock: the CRISTAL randomized trial. JAMA 2013;310:1809-17.

18. Vincent JL, Pinsky MR, Sprung CL, et al. The pulmonary artery catheter: in medio virtus. Crit Care Med 2008;36:3093-6.

19. McCabe WR, Jackson GG, Gram-negative bacteremia: I. Etiology and ecology. . Arch Intern Med 1962;110:847-55.

20. Knaus WA, Zimmerman JE, Wagner DP, et al. APACHE-acute physiology and chronic health evaluation: a physiologically based classification system. Crit Care Med 1981;9:591-7.

21. Teasdale G, Jennett B. Assessment of coma and impaired consciousness. A practical scale. Lancet 1974;2:81-4.

22. Le Gall JR, Lemeshow S, Saulnier F. A new Simplified Acute Physiology Score (SAPS II) based on a European/North American multicenter study. JAMA 1993;270:2957-63.

23. Vincent JL, Moreno R, Takala J, et al. The SOFA (Sepsis-related Organ Failure Assessment) score to describe organ dysfunction/ failure. On behalf of the Working Group on Sepsis-Related Problems of the European Society of Intensive Care Medicine. Intensive Care Med 1996;22:707-10.

24. Dellinger RP, Levy MM, Rhodes A, et al. Surviving sepsis campaign: international guidelines for management of severe sepsis and septic shock: 2012. Crit Care Med 2013;41:580-637.

25. Laird NM, Ware JH. Random-effects models for longitudinal data. Biometrics 1982;38:963-74.

26. Dellinger RP, Levy MM, Rhodes A, et al. Surviving sepsis campaign: international guidelines for management of severe sepsis and septic shock: 2012. Crit Care Med 2013;41:580-637.

27. Mann DL, Zipes DP, Libby P, et al. Braunwald's heart disease: a textbook of cardiovascular medicine. Elsevier Health Sciences 2014.

28. Parker MM, Shelhamer JH, Natanson C, et al. Serial cardiovascular variables in survivors and nonsurvivors of human septic shock: heart rate as an early predictor of prognosis. Crit Care Med 1987:15:923-9.

29. Sander O, Welters ID, Foëx P, et al. Impact of prolonged elevated heart rate on incidence of major cardiac events in critically ill patients with a high risk of cardiac complications. Crit Care Med 2005;33:81-8.

30. Orbegozo Cortés D, Gamarano Barros T, Njimi H, et al. Crystalloids versus colloids: exploring differences in fluid requirements by systematic review and meta-regression. Anesth Analg 2015;120:389-402.

31. Wiedemann HP, Wheeler AP, Bernard GR, et al. Lung, and Blood Institute Acute Respiratory Distress Syndrome (ARDS) Clinical Trials Network, Wiedemann HP.Comparison of two fluid-management strategies in acute lung injury. $N$ Engl J Med 2006;354:2564-75.

32. Malbrain ML, Marik PE, Witters I, et al. Fluid overload, deresuscitation, and outcomes in critically ill or injured patients: a systematic review with suggestions for clinical practice. Anaesthesiol Intensive Ther 2014;46:361-80.

33. Boyd JH, Forbes J, Nakada TA, et al. Fluid resuscitation in septic shock: a positive fluid balance and elevated central venous pressure are associated with increased mortality. Crit Care Med 2011;39:259-65.

34. US Food and Drug Administration. Hydroxyethyl starch solutions: FDA safety communication - boxed warning on increased mortality and severe renal injury and risk of bleeding. http://www.fda.gov/saf ety/medwatch/safetyinformation/safetyalertsforhumanmedicalpro ducts/ucm358349.htm (accessed 7 Apr 2015).

35. European Medicines Agency. PRAC confirms that hydroxyethylstarch solutions (HES) should no longer be used in patients with sepsis or burn injuries or in critically ill patients.2013 http://www. ema.europa.eu/docs/en_GB/document_library/Press_release/2013/ 10/WC500151964.pdf 